\title{
Analysis on the Difference of the Economic Development of Beijing, Tianjin and Hebei based on DMSP_OLS Night Light Data
}

\author{
Jian $\mathrm{Li}^{1,2}$, Chenguang Fan ${ }^{1}$ \\ ${ }^{1}$ Research Center of Circular Economy and Enterprises Sustainable Development, Tianjin \\ University of Technology, Tianjin 300384, China; \\ ${ }^{2}$ College of Management and Economics, Tianjin University, Tianjin 300072, China.
}

\begin{abstract}
Keywords: Stable Lighting Data, Relative Development Rate, Location Entropy.
\end{abstract}
\begin{abstract}
Based on the data of stable nighttime data, this paper uses the relative development rate and location entropy of Beijing-Tianjin-Hebei cities to quantitatively analyze the difference of urban economic development in Beijing-Tianjin-Hebei region from 2002 to 2015.According to the existing economic differences between Beijing and Tianjin and Hebei, we give the corresponding countermeasures and suggestions.
\end{abstract}

\section{Introduction}

With regional integrity, geographical connection, cultural similarity and strong humanistic affinity, Beijing-Tianjin-Hebei region is not only Chinese most important political, economic, cultural and technological center, but also Chinese participation in global competition and the first city to achieve modernization. As the core of the Bohai Sea economic circle, the Beijing-Tianjin-Hebei region is the largest industrial-intensive zone and the most economically developed region in the north of China. It is the economic region with the most development potential after the Yangtze River Delta and the Pearl River Delta. It is a new era of Chinese economic development of the new impetus, with good economic fundamentals, strong scientific and technological strength, geographical advantages and many other economic advantages. But in contrast, the level of economic development between Beijing and Tianjin and the former two there is a clear gap, itself is facing many problems to be solved. But in contrast, there is a clear gap on the level of economic development between Beijing, Tianjin and Hebei and the former two. And it is facing many problems to be solved. Therefore, it is of great theoretical and practical significance to scientifically evaluate the current economic disparity in the Beijing-Tianjin-Hebei region, to clarify the problems of regional development and to optimize the development direction in the future so as to provide scientific decision-making basis for its healthy development.

\section{Data and Method}

DMSP-OLS night light data is from the United States NOAA national geographic data center, including three kinds of annual average data: cloud observation frequency chart, the average light data, and stable lighting data. The spatial resolution of the data is 30 arc seconds, about $1 \mathrm{~km}$ at the equator. The gray value of the data range is $0-63$, and the value indicates that there is no light area. The larger the gray value is, the higher the brightness value is. Therefore, the data used in this paper is a stable lighting section, which eliminates the occasional noise effects such as clouds and fire, which range from 1 to 63.According to the study period, the image of F182013 was selected, and the DMSP / OLS data were cut with the vector administrative division map of Beijing-Tianjin-Hebei region as the boundary, and the nighttime data of Beijing-Tianjin-Hebei were obtained. BeijingTianjin-Hebei regional GDP and population data are from the "Beijing Statistical Yearbook", "Tianjin Statistical Yearbook", "Hebei Province Statistical Yearbook." This paper chooses the relative development rate and location entropy as two indicators to measure the economic development of the city of Beijing and Tianjin, its significance and specific formula are as follows: 
(1) Relative development rate: Relative development rates can measure the rate of development of each region over a given period of time relative to large areas.

$$
\text { Nich }=\frac{y_{2 i}-y_{1 i}}{y_{2}-y_{1}}
$$

(2) Location entropy: Economic location entropy can measure the Beijing-Tianjin-Hebei relative to the average level of development of Beijing-Tianjin-Hebei differences.

$$
Q_{i}=\frac{C_{i}}{P_{i}}
$$

\section{The Current Situation of Economic Development in Beijing, Tianjin and Hebei}

According to the research of the existing scholars, it can be seen that the nighttime light data has a positive correlation with the regional economic development. According to the nighttime data of the Beijing-Tianjin-Hebei region (see Figure 1), we can see that the lighting in Beijing and Tianjin is the brightest, Shijiazhuang and Tangshan are less than their. The rest of the city lights are extremely weak, and even worse in a dark. The economic development of Beijing-Tianjin-Hebei region is serious and it is a kind of polarization phenomenon. It is an urgent problem to be solved in the process of integrating Beijing, Tianjin and Hebei. Therefore, it is necessary to quantify the economic development of the city of Beijing, Tianjin and Hebei.

\section{The Evolution of Relative Economic Development Rate of Beijing, Tianjin and Hebei}

By calculating the relative development rates of real GDP in the cities of Beijing, Tianjin and Hebei in 2002-2008 and 2008-2015 (see Figure 2).It can be seen from the figure that there is obvious regional difference in the relative development rate of the cities in Beijing, Tianjin and Hebei provinces: the relative development rate of Beijing, Tianjin and Tangshan is always in the forefront of Beijing-Tianjin-Hebei region, far more than other cities; The relative development rate of Beijing, Tianjin and Tangshan is always greater than 1 in two periods, indicating that the increase of GDP is greater than that of Beijing-Tianjin-Hebei region. The relative development rates of Qinhuangdao, Handan, Xingtai, Baoding, Zhangjiakou, Chengde, Cangzhou and Hengshui are always lower than 1 in two periods, indicating that their economic development is slower and lower than the average development level of the whole region. Compared with the relative development rate of the two periods, the economic development of Hebei cities in 2008-2015 has slowed down. The economic development of Shijiazhuang, Tangshan and Hengshui has improved slightly compared with the previous period. Overall, there were three cities with a relative development rate of more than 1 in 2002-2008, and the number of cities with a relative development rate of more than 1 in 2008-2015 increased to five, indicating that the regional economic gap of Beijing, Tianjin and Hebei was slightly slowed down, but the gap was still significant.

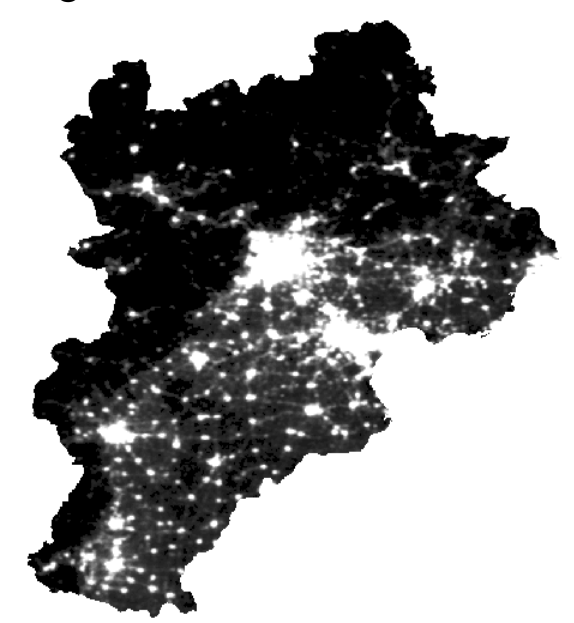

Fig.1 Beijing-Tianjin-Hebei night light distribution map 


\section{Analysis of Economic Location Entropy of Beijing, Tianjin and Hebei}

According to the formula 2, we can calculate the economic location entropy of the cities in Beijing, Tianjin and Hebei from 2002 to 2015 (see Table 1).From Table 1 we can see that Beijing, Tianjin, Tangshan is always the economically developed areas of the Beijing-Tianjin-Hebei region.As the capital of China and Beijing as a municipality directly under the jurisdiction of the city, the advantages of resources, traffic developed, location entropy in the Beijing-Tianjin-Hebei region has been far ahead, and Tangshan as Chinese heavy industry developed areas, industrial development contributed great economic development. The location entropy of Shijiazhuang and Qinhuangdao are close to 1 in 2002-2005, which belongs to the economically developed areas, but since 2005, there are declining trends. Hebei Province, in addition to Tangshan, Shijiazhuang, Qinhuangdao, the rest of the city in 2002-2015 is basically always belong to the economic backward areas, and with the passage of time, the city's location entropy in the overall decline in the trend.In general, the location entropy of Beijing and Tianjin is basically increasing year by year, while the cities in Hebei Province are decreasing year by year, indicating that the economic gap between Beijing and Tianjin is becoming more and more obvious over time.

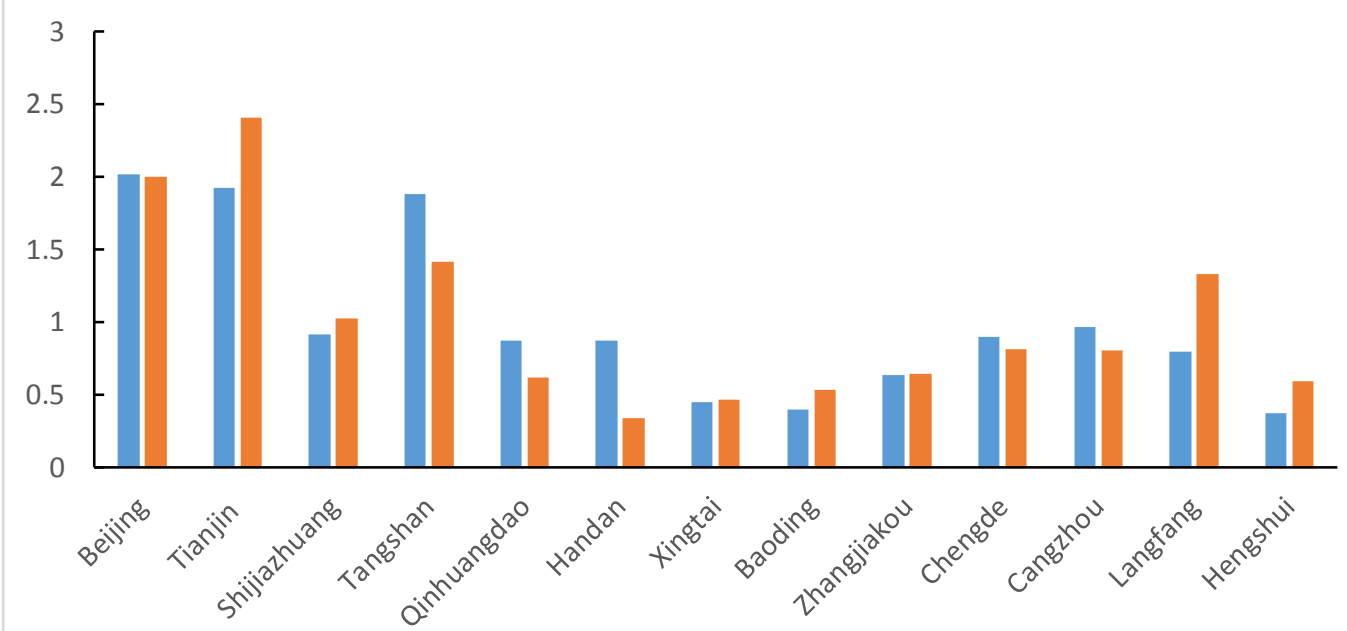

Fig. 2 The relative development rate in cities of the Beijing,Tianjin and Hebei region

Tab.1 The location entropy of all cities in the Beijing,Tianjin and Hebei region in 2002-2015

\begin{tabular}{|c|c|c|c|c|c|c|c|c|c|c|c|c|c|}
\hline $\begin{array}{c}\text { Year } \\
\mathrm{s}\end{array}$ & $\begin{array}{c}\text { Beijin } \\
\mathrm{g}\end{array}$ & $\begin{array}{c}\text { Tianji } \\
n\end{array}$ & $\begin{array}{c}\text { Shijiazhuan } \\
\text { g }\end{array}$ & $\begin{array}{c}\text { Tangsha } \\
n\end{array}$ & $\begin{array}{c}\text { Qinhuangda } \\
\text { o }\end{array}$ & $\begin{array}{c}\text { Handa } \\
n\end{array}$ & $\begin{array}{c}\text { Xingta } \\
\mathrm{i}\end{array}$ & $\begin{array}{c}\text { Baodin } \\
\mathrm{g}\end{array}$ & $\begin{array}{c}\text { Zhangjiako } \\
\text { u }\end{array}$ & $\begin{array}{c}\text { Chengd } \\
\mathrm{e}\end{array}$ & $\begin{array}{c}\text { Cangzho } \\
\mathrm{u}\end{array}$ & $\begin{array}{c}\text { Langfan } \\
\text { g }\end{array}$ & $\begin{array}{c}\text { Hengshu } \\
\text { i }\end{array}$ \\
\hline 2002 & 2.1399 & 1.6892 & 0.9936 & 1.1873 & 0.9393 & 0.5816 & 0.5010 & 0.5824 & 0.4676 & 0.4230 & 0.5936 & 0.9063 & 0.6429 \\
\hline 2003 & 2.0946 & 1.7364 & 0.9942 & 1.2048 & 0.9303 & 0.5845 & 0.5065 & 0.5641 & 0.4666 & 0.4299 & 0.6074 & 0.8966 & 0.6305 \\
\hline 2004 & 2.0317 & 1.7342 & 0.9820 & 1.2634 & 0.9068 & 0.5983 & 0.5217 & 0.5631 & 0.4906 & 0.4596 & 0.6285 & 0.8558 & 0.6309 \\
\hline 2005 & 2.6458 & 1.7857 & 0.8741 & 1.2873 & 0.7996 & 0.0603 & 0.4574 & 0.4453 & 0.4189 & 0.4524 & 0.7491 & 0.7197 & 0.5645 \\
\hline 2006 & 2.4887 & 1.7397 & 0.8169 & 1.2440 & 0.7452 & 0.5823 & 0.4384 & 0.4108 & 0.4042 & 0.4456 & 0.7026 & 0.6985 & 0.4902 \\
\hline 2007 & 2.5223 & 1.7228 & 0.8087 & 1.2549 & 0.7894 & 0.5870 & 0.4195 & 0.4005 & 0.4053 & 0.4936 & 0.6847 & 0.7197 & 0.4277 \\
\hline 2008 & 2.2691 & 1.8445 & 0.8259 & 1.3730 & 0.7959 & 0.6031 & 0.3938 & 0.3894 & 0.4407 & 0.5443 & 0.6797 & 0.7243 & 0.4121 \\
\hline 2009 & 2.4723 & 1.9456 & 0.7782 & 1.3167 & 0.7099 & 0.5418 & 0.3725 & 0.3795 & 0.4387 & 0.5180 & 0.6362 & 0.7036 & 0.3788 \\
\hline 2010 & 2.4356 & 2.0331 & 0.7463 & 1.3198 & 0.7006 & 0.5320 & 0.3594 & 0.3833 & 0.4502 & 0.5174 & 0.6543 & 0.6999 & 0.3855 \\
\hline 2011 & 2.3449 & 2.0923 & 0.7548 & 1.3614 & 0.6808 & 0.5247 & 0.3575 & 0.3892 & 0.4413 & 0.5439 & 0.6487 & 0.6992 & 0.3879 \\
\hline 2012 & 2.3229 & 2.1884 & 0.7546 & 1.3321 & 0.6596 & 0.5134 & 0.3454 & 0.3913 & 0.4439 & 0.5286 & 0.6369 & 0.6980 & 0.3852 \\
\hline 2013 & 2.3206 & 2.2420 & 0.7594 & 1.2980 & 0.6255 & 0.4825 & 0.3295 & 0.3909 & 0.4419 & 0.5270 & 0.6257 & 0.7206 & 0.3746 \\
\hline 2014 & 2.3895 & 2.3106 & 0.7535 & 1.2346 & 0.6074 & 0.4469 & 0.3183 & 0.3789 & 0.4300 & 0.5268 & 0.6091 & 0.7216 & 0.3792 \\
\hline 2015 & 1.7083 & 1.7258 & 0.8207 & 1.2630 & 0.6568 & 0.4837 & 0.3905 & 0.4193 & 0.4978 & 0.6213 & 0.6755 & 0.8752 & 0.4440 \\
\hline
\end{tabular}

\section{Conclusion}

This paper analyzes the present situation of economic development in Beijing and Tianjin by using stable nighttime light data, and uses the relative development rate and location entropy to quantify the economic development of Beijing-Tianjin-Hebei cities, and draw the economic situation between Beijing-Tianjin-Hebei cities. It is concluded that the economic development difference between Beijing and Tianjin is increasing year by year, and the economic imbalance is serious. It is necessary to formulate positive policies to improve the situation. 


\section{References}

[1]. Zhang X B, Kanbur R. What Difference Do Polarization Measures Make? An Application to China [J]. Journal of Development Stud-ies, 2001, 37(31): 85 - 98.

[2]. Wen Y, Thill J C. Identification, structure and dynamic characteristics of the Beijing-TianjinHebei mega-city region [J]. Cambridge Journal of Regions, Economy and Society, 2016, 9(3):rsw023.

[3]. Li C, Wu K, Wu J. Urban land use change and its socio-economic driving forces in China: a case study in Beijing, Tianjin and Hebei region [J]. Environment Development \& Sustainability, 2017:1-15.

[4]. Yao Y F, Chen J, Zhang X M, et al. Economic Influences, Spillover Effects and Feedback Effects Among Beijing-Tianjin-Hebei Region[J]. Urban \& Environmental Studies, 2016. 